Brit. J. industr. Med., 1965, 22, 154.

\title{
PNEUMOCONIOSIS IN A COALWORKER FROM CEYLON
}

\author{
BY \\ G. H. COORAY and P. R. WIKRAMANAYAKE \\ From the Department of Pathology, University of Ceylon, and \\ The General Hospital, Colombo, Ceylon
}

(RECEIVED FOR PUBLICATION NOVEMBER 23, 1964)

\begin{abstract}
This report includes the clinical, radiological, morbid anatomical, and histological findings in the lungs of a man who for a continuous period of 45 years had been engaged in the loading and unloading of coal in ships and trains. He presented as a case of congestive cardiac failure with signs of severe pulmonary hypertension. The chief feature in the lungs was the presence of silicoticlike nodules which were revealed on histological examination. Fine particles of siliceous material were identified on examination with the polarizing microscope.

This case is an example of pneumoconiosis caused by prolonged exposure to siliceous carbon. It is the first of its kind to be reported from this country.
\end{abstract}

\section{Case Report}

G.A.W.J. aged 67 years was admitted to the General Hospital, Colombo in congestive cardiac failure.

His occupational history was interesting. He was employed 45 years ago by a shipping company in Colombo to unload coal from ships in the harbour. He continued in this job for 23 years and he stated that after a day's work he was completely covered in soot. He had no respiratory distress at that time but he noticed that his sputum was black. On leaving this post he was employed in the Ceylon Government Railway in a similar occupation where he used to load and unload coal.

About three years ago he began to get breathless, and this symptom became progressively worse until the present episode when he developed congestive cardiac failure.

On examination he was dyspnoeic, making use of his accessory muscles of respiration. His feet were oedematous. There was no finger clubbing, but he had distended forearm veins and warm hands, and the tongue showed cyanosis. The pulse was 80 per minute, moderately collapsed and regular, and the blood pressure was $110 / 60 \mathrm{~mm}$. $\mathrm{Hg}$. The jugular venous pressure was raised (at $45^{\circ}$ ), the ' $a$ ' wave which was very prominent being $5 \mathrm{~cm}$. above the ' $\mathrm{v}$ ' wave. On auscultation there was a presystolic gallop best heard at the sternal edge of the third left intercostal space and an ejection systolic murmur in the pulmonary area. The pulmonary component of the second sound was quite loud. These physical signs were clear in spite of the emphysematous lungs.

He had a barrel-shaped chest with expansion of only $\frac{1}{2}$ in. on maximal inspiration. The area of cardiac dullness was diminished. The percussion note was hyper resonant, particularly at the apices, and rhonchi were heard all over and crepitations at the bases.

Examination of the abdomen revealed no abnormality other than the liver which was palpable two fingerbreadths below the costal margin. Its upper border was in the right sixth intercostal space.

Laboratory Investigations.-W.B.C. 7600/c.mm.; polymorphs $65 \%$, lymphocytes $30 \%$, eosinophils $4 \%$, hyaline cells $1 \%$; haemoglobin $68 \mathrm{~g} . / 100 \mathrm{ml}$. (Sahli). The erythrocyte sedimentation rate was $66 \mathrm{~mm}$. in the first hour. Sputum for acid-fast bacilli was negative on six successive examinations. Blood urea was $40 \mathrm{mg}$. $/ 100 \mathrm{ml}$. The electrocardiogram showed a vertical heart with right axis deviation. There were prominent right atrial ' $p$ ' waves (' $p$ ' pulmonale) and inverted $T$ waves in leads $V_{1}$ to $V_{4}$. The $R$ wave in lead $V_{1}$ was $2 \mathrm{~mm}$.

On radiological examination massive shadows were seen chiefly in the right middle and lower zones, from which linear shadows radiated in various directions (Fig. 1). The left upper zone showed a moderate degree of emphysema. The cardiac shadow was enlarged, the right ventricle and pulmonary artery being prominent. 


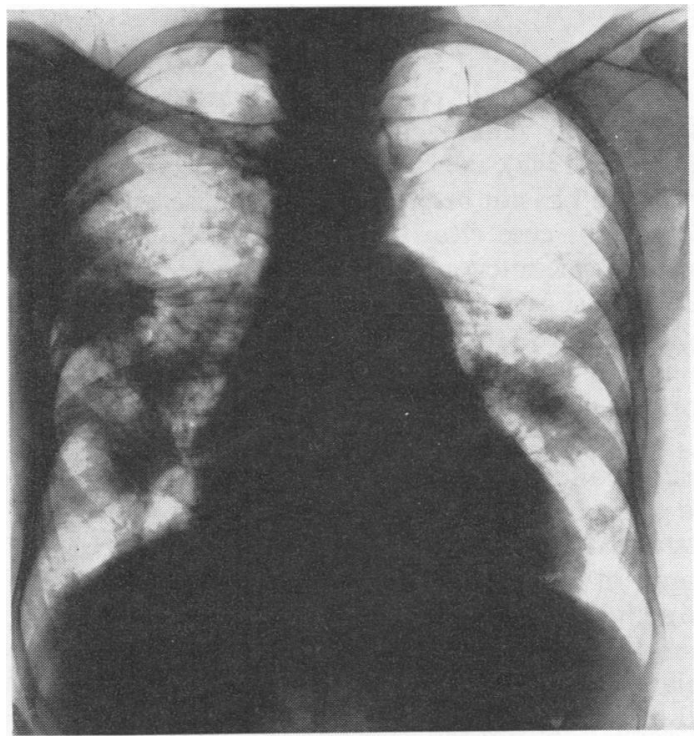

Fig. 1

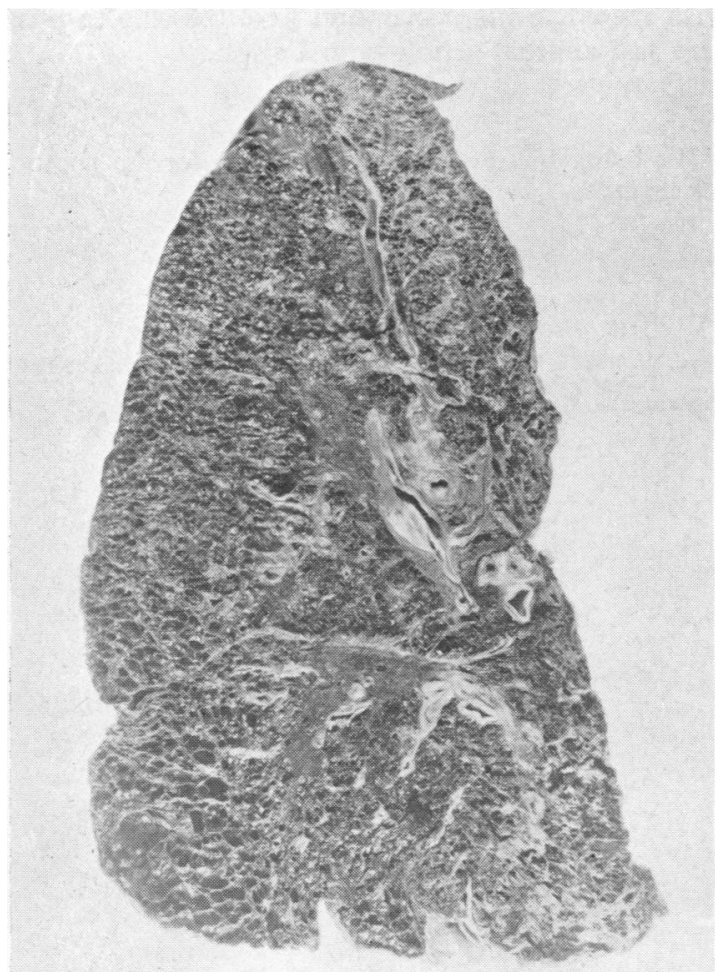

FIG. 2

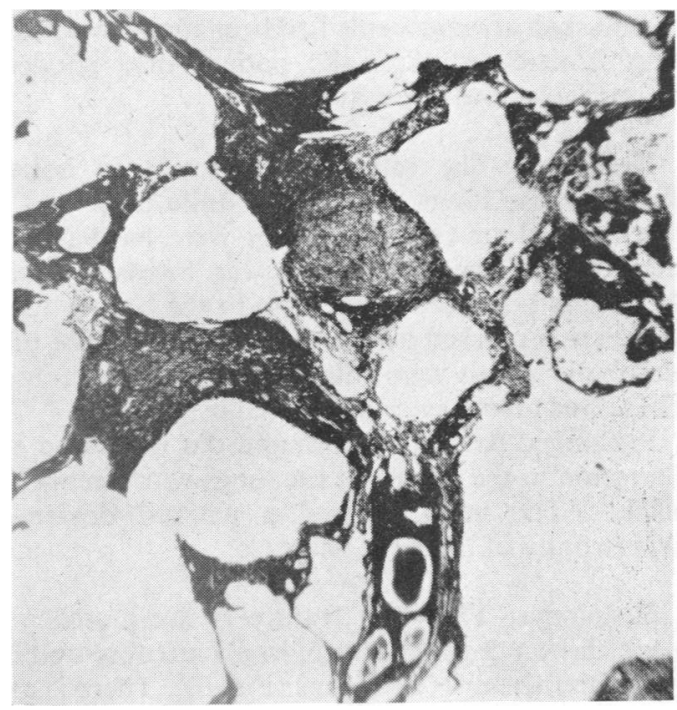

Fig. 3

FIG. 1.-Chest radiograph showing massive fibrosis chiefly in the right middle and lower zones.

FIG. 2.-Sectional surface of lung which is black and emphysematous. $\times \frac{1}{3}$.

FIG. 3.-Emphysematous lung showing carbon deposits as well as a small nodule. $H$. and $E$. $\times 50$.

Fig. 4.-High-power view of nodule in Fig. 3 showing resemblance to a silicotic nodule. Reticulin $\times 250$.

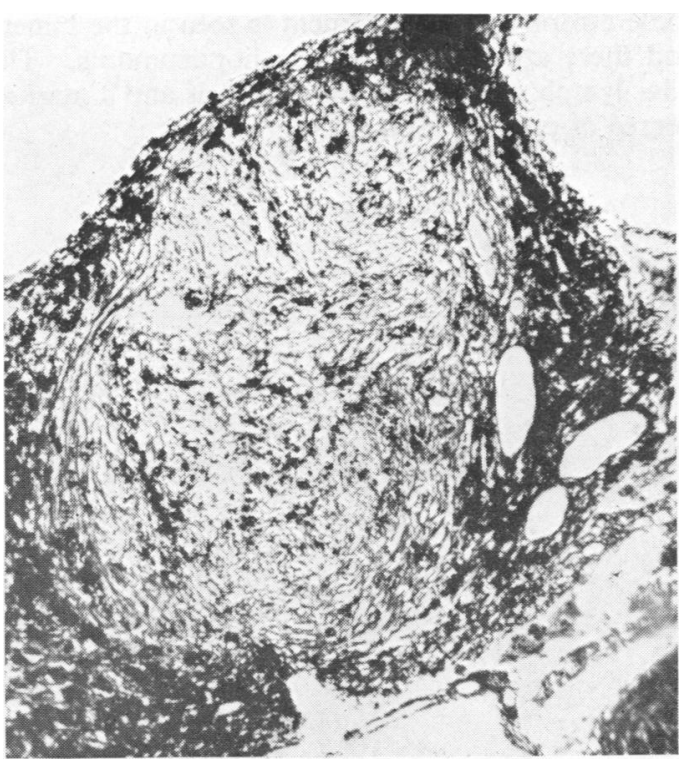

FIG. 4 
Although arrangements had been made to perform lung function studies, the patient died suddenly before these could be carried out.

Necropsy.-The relevant features were noticed chiefly in the lungs which were quite large and jet black in colour (Fig. 2). They were hard in consistency and the cut section was intensely black. There was a noticeable increase in the fibrous tissue as well as a marked degree of emphysema. The hilar lymphatic glands were enlarged and black in colour. There was no evidence of tuberculosis.

Prolonged fixation in formalin did not cause any alteration in the colour of the lungs which remained black. The heart showed a marked degree of hypertrophy of the right ventricle.

Histology.-The chief feature is the presence of black carbon deposits which, in places, obscured the interstitial tissue of the lungs (Fig. 3). There is also a marked degree of emphysema. These deposits are in the form of nodules, some of which show whorled collagen fibres resembling silicotic nodules (Fig. 4). When examined by polarized light, refractile particles are seen in these nodules. Carbon pigment is also seen in the adventitial coats of blood vessels. The portions of the interstitial tissue unobscured by carbon show a marked increase of collagen fibres as revealed by van Gieson stain. Haemosiderin-laden phagocytes ('heart failure' cells) are seen in some of the alveoli. The blood vessels show a marked degree of intimal thickening. The mucosa of the bronchi and bronchioles is desquamated in places and shows some atrophy. Black pigment is seen in the lumen, and there are patches of bronchopneumonia. The hilar lymph nodes show some fibrosis and a marked degree of pigmentation.

\section{Discussion}

Although certain changes in the lungs have been described in plumbago workers in Ceylon (Dassanayake, 1948), coal as a cause of pneumoconiosis in Ceylon has not been reported. All the evidence in the present case clearly indicates the fact that this patient's pneumoconiosis was due to the inhalation of coal dust over a prolonged period. This condition is similar to that of exposure experienced by 'trimmers' on ships who are known to develop coalworkers' pneumoconiosis (Boyd, 1958).

The patient presented as a case of congestive cardiac failure. However, unusual features, such as the presence of a barrel-shaped chest and respiratory distress, with the patient making use of his accessory muscle of respiration, drew attention to the fact that the aetiology was that of chronic lung disease leading to right heart failure, i.e., chronic cor pulmonale. This itself is not very common in Ceylon except in asthmatics who have had the disease for several years. Exposure to dust is almost unknown; those who may be so exposed, e.g., plumbago (graphite) miners, are not known to develop chronic cor pulmonale. The careful interrogation of this patient with regard to his occupation gave the clue to this rare and unusual aetiology in Ceylon.

We thank Mr. P. D. S. Amarasekera for the photomicrographs.

\section{REFERENCES}

Boyd, W. (1958). Pathology for the Physician, 6th ed., p. 227. Lea and Dassanayake, W. L. P. (1948). Brit. J. industr. Med., 5, 141. 